\title{
Formalização da logística de suprimentos: caso das montadoras e fornecedores da indústria automotiva brasileira
}

\author{
Patrícia Guarnieria,**, Kazuo Hatakeyama ${ }^{\mathrm{b}}$ \\ a,*pgguarnieri@yahoo.com.br, UFPE, Brasil \\ bkhatakeyama@uol.com.br, UTFPR, Brasil
}

\begin{abstract}
Resumo
O setor automotivo apresenta iniciativas consideráveis na gestão da cadeia de suprimentos (GCS), que merecem ser destacadas. 0 objetivo principal da presente pesquisa foi verificar o nível de formalização na logística de suprimentos (LS) das montadoras e fornecedores da indústria automotiva brasileira. Para tanto, realizou-se uma pesquisa aplicada, exploratória e descritiva, por meio do método indutivo que, do ponto de vista da abordagem do problema, caracterizase como qualitativa. 0 procedimento técnico utilizado foi o levantamento de dados, e a coleta foi realizada por meio de questionários de pesquisa. A amostra foi composta de 23 montadoras e 50 fornecedores provenientes da indústria automotiva brasileira. Constatou-se que as práticas adotadas por ambos são convergentes, o que se constitui em aspecto essencial na implementação efetiva do conceito de GCS, no entanto ressalta-se que nas montadoras essas práticas estão mais desenvolvidas.
\end{abstract}

Palavras-chave

Indústria automotiva. Gestão da cadeia de suprimentos. Logística de suprimentos.

\section{Introdução}

A integração de todas as atividades logísticas, desde o pedido do cliente ao fornecedor até a entrega ao consumidor final, permeada por serviços e informações que agreguem valor, é uma realidade no ambiente empresarial. No entanto, essa integração exige iniciativas de gestão efetiva das cadeias de suprimentos (CS), viabilizadas por meio da gestão da cadeia de suprimentos (GCS). 0 GCS engloba não somente os processos de negócios, mas também o relacionamento com clientes e fornecedores visando parcerias estratégicas, que beneficiem todos os componentes da cadeia.

0 segmento automotivo pode ser considerado representativo nesse sentido, pois apresenta iniciativas consideráveis na GCS. De acordo com Pires (2004), durante os últimos cem anos a indústria automotiva se desenvolveu e tornou-se um dos segmentos industriais mais representativos. Por seu pioneirismo e nível de competitividade, posicionou-se em termos de inovações tecnológicas e gerenciais, tornando-se um verdadeiro referencial para o ambiente industrial.
0 Brasil recebeu durante os últimos dez anos aproximadamente US\$30 bilhões de investimentos no segmento automobilístico, segundo Pires (2004). Uma parcela desse valor foi para a atualização tecnológica das unidades já existentes, porém a maior parcela destinou-se à construção de novas unidades sob a perspectiva do conceito de GCS. Isto possibilitou ao país tornar-se exemplo mundial, por possuir em seu território instalações fabris atualizadas de montadoras automotivas de grande porte de diversos paises do mundo, especialmente em termos de processos logísticos e GCS.

A CS da indústria automotiva envolve montadoras, fornecedores, varejistas e cliente final, portanto um simples atraso gerado por qualquer um dos membros dessa cadeia pode parar a produção por falta de componentes. Devido à complexidade de suas operações, o sucesso do gerenciamento de todos esses componentes depende da GCS, principalmente no que tange à redução de custos logísticos, à integração e à troca de informações. Uma das tendências mundiais é que fique a cargo das montadoras a coordenação dessa cadeia, enquanto 
os fornecedores atuam no desenvolvimento do produto e na execução dos processos de montagem dos veículos.

0 presente trabalho pretendeu verificar os principais fatores que impactam no suprimento da produção das indústrias automotivas. Para tanto, foi realizada uma pesquisa aplicada, exploratória e descritiva, por meio do método indutivo que, do ponto de vista da abordagem do problema, caracteriza-se como qualitativa. 0 procedimento técnico utilizado foi o levantamento de dados, e a coleta foi realizada por meio de questionários de pesquisa.

Percebe-se que as práticas adotadas por montadoras e fornecedores convergem, e esse fato é positivo considerando-se que a padronização nas iniciativas das empresas envolvidas na mesma CS se constitui em aspecto essencial na implementação efetiva do conceito de GCS e no alcance dos objetivos mútuos. No entanto, ressalta-se que nas montadoras essas práticas estão mais desenvolvidas do que nos fornecedores.

\section{Logística integrada (Ll) e gestão da cadeia de suprimentos (GCS)}

0 potencial considerável de evolução da logística e os impactos operacionais significativos que representa nas organizações a tornam crítica para o sucesso da empresa em penetrar em novos mercados. Consequentemente, tanto a logística como o gerenciamento de operações devem ser implementados em um novo contexto global (DORNIER et al., 1998).

Atualmente, o gerenciamento logístico busca o foco na integração das atividades da empresa e na intensa troca de informações, pois, considerando que todas elas fazem parte de um processo único, cujo objetivo é satisfazer as necessidades do cliente final, não há razões para gerenciá-las separadamente, incorrendo em riscos desnecessários à empresa, como pode ser visualizado na Figura 1.

0 processo logístico inicia com o cliente, gerando demanda para a $\mathrm{LS}$, que trata das relações entre a empresa e seus fornecedores, que por sua vez supre a produção e prepara o produto para a distribuição ao cliente final. Após o consumo do produto ele pode ser reintegrado ao processo produtivo ou de negócios por meio da logística reversa através da reciclagem, remanufatura, reuso, entre outros.

De acordo com Ching (2001), o alto desempenho na cadeia de logística integrada (LI) requer maior qualidade nos processos, foco nas necessidades do serviço prestado ao cliente, provendo melhoria na estrutura de custos por meio de todo o processo e redução de prazos de entrega. Para Arbache et al.

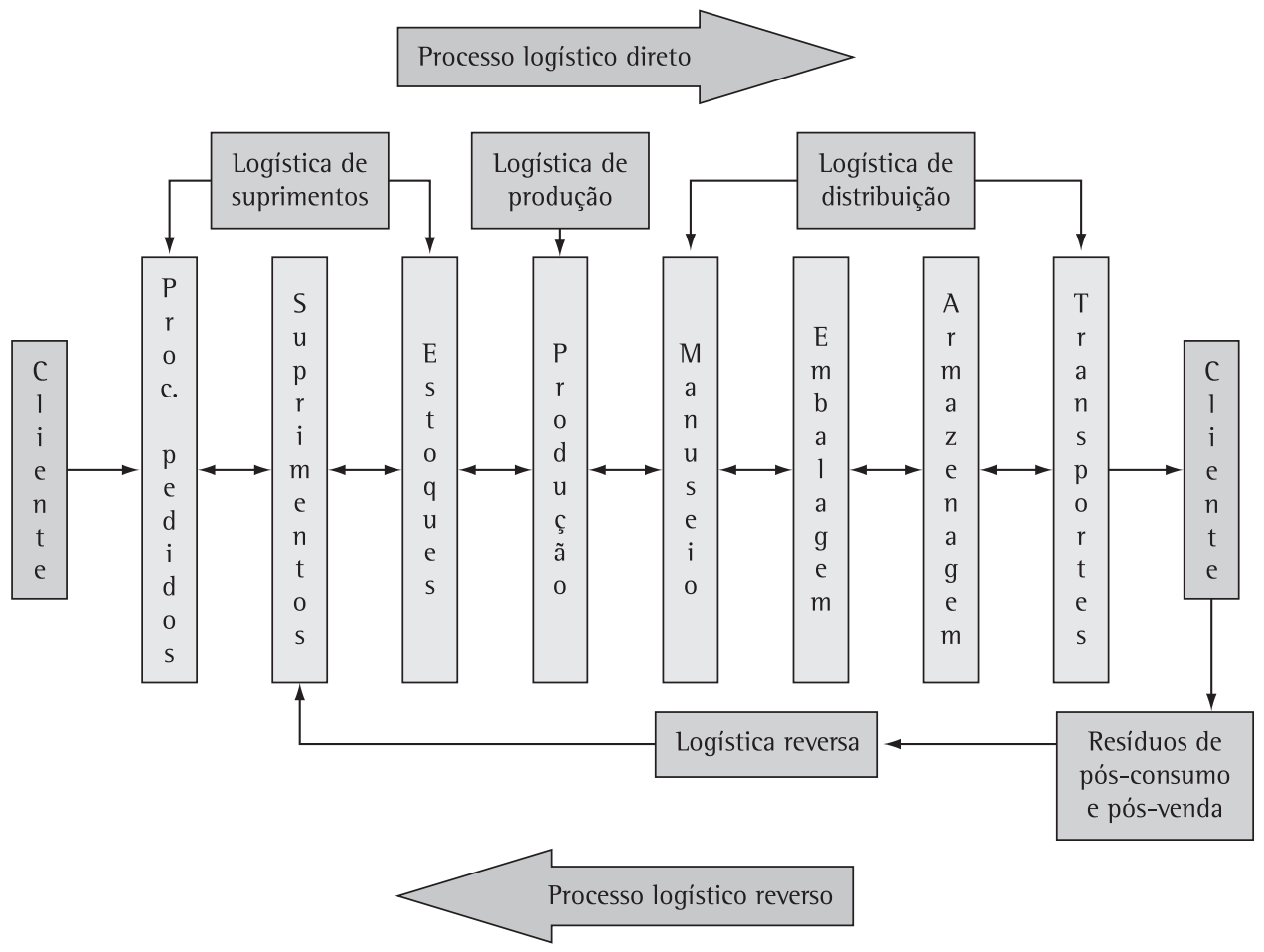

Figura 1. Processo logístico integrado. Fonte: Os autores. 
(2004), a Ll é uma forma organizada de perceber todos os processos que geram valor para o cliente final de um produto, independentemente de onde ele esteja sendo executado, se na própria empresa ou em alguma outra com a qual há algum tipo de relacionamento.

Essa mudança conceitual na forma como as empresas gerenciam sua relação com o produto ofertado ao mercado, passando a compartilhar com outros componentes da cadeia os processos-chave do negócio, é justamente o GCS (ARBACHE et al., 2004). Wanke (2003) ressalta que o GCS é uma tarefa mais complexa que a gerência logística dos fluxos de produtos, serviços e informações relacionadas do ponto de origem para o ponto de consumo.

Essa complexidade deve-se ao fato de que o GCS envolve, além do gerenciamento logístico de forma integrada, estratégias de relacionamentos com fornecedores e clientes visando maior durabilidade nos negócios, por meio de parcerias baseadas na confiança e na colaboração que geram vantagens competitivas. Muitas empresas descobriram que por meio dessas parcerias poderiam melhorar o projeto de produto, estratégias de marketing e de serviço ao cliente, além de encontrar formas mais eficientes de trabalharem juntas.

Percebe-se que, quanto mais estreito o relacionamento entre fornecedor e comprador, maiores serão as chances de as habilidades de cada parte serem aplicadas para benefício mútuo. De acordo com Christopher (1997), muitas empresas descobriram que por meio da forte cooperação com os fornecedores poderiam melhorar o projeto do produto, praticar engenharia de valor dos componentes e geralmente descobrir meios mais eficientes de trabalharem juntos.

lgualmente, de acordo com Marini (2003), um dos principais objetivos do GCS é atender o consumidor final com maior eficiência, tanto pela redução de custos quanto pela adição de mais valor aos produtos finais. A queda dos custos tem sido obtida mediante a diminuição do volume de transações de informações e papéis, dos custos de transporte e estocagem, da eliminação dos pontos de controle de qualidade e da redução da variabilidade da previsão de demanda de produtos e serviços.

$\mathrm{Na}$ indústria automotiva, segundo Christopher (1997), aproximadamente $12 \%$ dos custos de materiais para o fabricante de automóveis são incorridos pelos custos logísticos dos fornecedores. No relacionamento tradicional de adversários, o fabricante de automóveis poderia procurar reduzir seus custos de materiais pressionando a margem de lucro do fornecedor de componentes, o que no relacionamento integrado não ocorre.

\section{A necessidade, as vantagens e as capacidades requeridas na integração da cadeia de suprimentos}

Sob essa nova ótica dos negócios, as empresas devem conhecer as tecnologias que serão implementadas e a flexibilidade para resolver problemas, inovando e permitindo a criação de um canal de comunicação aberto para que possa haver integração entre seus processos. É premente a troca de informações, a gestão das atividades e tecnologias avançadas de logística, o desenvolvimento de novos projetos que incentivem a existência de confiança e de cooperação direta entre parceiros (MARINI, 2003).

Christopher (1997) declara que a maior implicação dos desafios para uma organização ágil seja talvez a prioridade que deve ser dada à integração, não somente a integração interna da organização, mas também com seus fornecedores, distribuidores e clientes finais, que é buscada pelo conceito de GCS. Pires (2004) salienta que em muitos setores industriais já não é suficiente apenas integrar as operações, estruturas e infraestruturas internas com a estratégia competitiva: a tendência é a integração dos processos internos da empresa com fornecedores externos e clientes, formando uma CS com propósitos e procedimentos definidos e consistentes. Dessa forma, a vantagem competitiva obtida conjuntamente, ao longo da CS, torna-se sustentável e mais difícil de ser copiada e ultrapassada pelos concorrentes.

As novas exigências têm sido seguidas como referência para que as montadorase seus fornecedores diretos possam manter a eficiência não só nas suas atividades diretas, como também ao longo da cadeia. Destacam-se entre as principais exigências das montadoras para com os fornecedores: saúde financeira, integração eletrônica, desenvolvimento de novos produtos e processos, padrões internacionais de custo e qualidade, logística confiável, redução de desperdícios, entre outros (PIRES, 2004).

A qualidade e a confiabilidade têm se tornado mais importantes com a introdução da produção just-in-time (JIT) e com o uso dos sistemas ERP, pois dessa forma os componentes e matérias-primas somente são solicitados quando existe a demanda, o que reduz, sensivelmente, os custos com inventário. As parcerias na CS permitem às montadoras gerenciar fornecedores e subfornecedores e cooperar e maximizar a lucratividade para todos os parceiros (KILLEN et al., 2004).

De acordo com Scavarda e Hamacher (2004), uma das questões críticas da GCS da indústria 
automotiva é o desenvolvimento de capacidades que permitem que atividades e processos sejam integrados ao longo da CS. Os mesmos autores afirmam que essas capacidades são conjuntos de ações que possibilitam a criação, produção e comercialização de determinado produto, gerando valor agregado ao consumidor final no término do processo.

Estes fatores ou conjunto de ações, de acordo com Ross (1998) apud Scavarda e Hamacher (2004), apontam que outro fator crítico para o sucesso da GCS é a racionalização e integração dos processos dos negócios da CS, das capacidades inovadoras, por parte dos membros da cadeia, antecipando o potencial competitivo e abrindo novas áreas de competição.

No Quadro 1 é possível visualizar as capacidades apontadas pelos autores Scavarda eHamacher (2003) e Marini (2003), necessárias à nova configuração de relacionamentos entre fornecedores e montadoras da indústria automotiva.Essas capacidades, discriminadas no Quadro 1, formam um conjunto de conceitos e técnicas diretamente relacionadas à LS, incluídas em subáreas da logística que impactam diretamente no alcance dos objetivos de redução de estoques, tempos de fornecimento, custos, controle de qualidade, disponibilidade dos materiais no momento correto, evitando paradas de produção e consequentemente prejuízos para a CS. Essas subáreas são: suprimentos, transportes, armazenagem, administração de estoques e sistemas de informações. Para explicitar o entendimento da relação que cada uma dessas atividades e o conjunto de ações que visam racionalizá-las e integrá-las possuem com o processo de suprimento da produção, nas indústrias automotivas, julgou-se necessária a breve descrição de suas particularidades, que se apresentam a seguir.

\section{Conceitos e ferramentas tecnológicas utilizadas no gerenciamento logístico da cadeia de suprimentos}

\subsection{Suprimentos (compras)}

A atividade de suprimentos em uma empresa fornece apoio fundamental ao sucesso do sistema logístico - é ela que supre o processo produtivo, com todas as necessidades de materiais e, além disso, contribui com uma parcela significativa na redução de custos da empresa, por meio de negociações de preços, na busca de materiais alternativos e do desenvolvimento de fornecedores.

Além dessas funções básicas, a atividade de suprimentos, segundo a nova configuração da GCS, desempenha algumas ações que apoiam o processo de abastecimento da produção. De acordo com Ching (2001) e Christopher (1997), são o desenvolvimento de relacionamentos estratégicos com fornecedores e de novos materiais; qualificação e redução do número de fornecedores.

\subsection{Transportes}

Um fator importante para a análise dos transportes de uma empresa é a forma pela qual ela realiza suas compras e recebe seus suprimentos. Existem dois meios para operar as compras: pelo sistema CIF - Cost Insurance and Freight (transporte por conta do fornecedor) ou pelo sistema FOB Free on Board (transporte por conta da empresa). De acordo com Dias (1993), a tendência normal dos setores de compras ou suprimentos é optar pelo sistema CIF, de forma a receber a carga em seus depósitos, deixando os fornecedores incumbidos de escolher os meios de transporte para o cumprimento dos prazos de entrega.

Quadro 1. Capacidades exigidas para a nova configuração de relacionamento entre fornecedores e montadoras.

\begin{tabular}{|c|l|}
\hline Autores & \multicolumn{1}{|c|}{$\begin{array}{c}\text { Capacidades exigidas para a nova configuração de relacionamento entre } \\
\text { fornecedores e montadoras da indústria automotiva }\end{array}$} \\
\hline $\begin{array}{c}\text { Scavarda e Hamacher } \\
\text { (2003) }\end{array}$ & $\begin{array}{l}\text { Co-design, e-commerce, e-procurement (compras por meio eletrônico), Early Supplier Involvement } \\
\text { - ESI (envolvimento antecipado do fornecedor), follow design, follow sourcing, global sourcing, } \\
\text { folant Representatives - IPR, just-in-time (JIT), milk run (MR), modularidade, parques de } \\
\text { fornecedores (condomínio industrial e consórcio modular), postergação, Quick Response - QR } \\
\text { (resposta rápida) e Vendor Management Inventory - VMl (gerenciamento do inventário do } \\
\text { vendedor). }\end{array}$ \\
\hline Marini (2003) & $\begin{array}{l}\text { 0 papel estratégico da atividade logística de compras/suprimentos; avaliação e seleção de } \\
\text { fornecedores; gestão da qualidade; desenvolvimento conjunto de produtos (coprodução); } \\
\text { componentes logísticos (número de fornecedores, tempo de suprimento, custo de suprimento, } \\
\text { reabastecimento just-in-time, transporte, milk run, cross-docking, sistemas de informações). }\end{array}$ \\
\hline
\end{tabular}

Fonte: Os autores. 
A atividade de transportes, de acordo com o novo conceito de GCS, deve ser administrada em conjunto com as demais atividades da empresa, pois as decisões tomadas podem influenciar diretamente o correto andamento da empresa. No presente trabalho, destaca a importância que representa para o abastecimento da produção.

\subsection{Armazenagem}

Uma instalação de armazenagem, de acordo com Arbache et al. (2004), pode desempenhar vários papéis na estrutura de distribuição adotada por uma empresa: recepção e consolidação de produtos de vários fornecedores, para posterior distribuição a diversas lojas de uma rede; recepção de produtos de uma fábrica e distribuição para diversos clientes.

Com o intuito de racionalizar as práticas de armazenagem, surge nas últimas décadas o crossdocking, uma das principais práticas logísticas a serviço da GCS, conduzindo a consecução de alguns de seus pressupostos, como a redução de estoques em armazéns, melhora no fluxo de materiais, redução de lead times e de custos com transportes. (PIRES, 2004).

Lacerda (2000) afirma que o cross-docking inicia quando carretas completas chegam de múltiplos fornecedores, e então é realizado um processo de separação dos pedidos, com a movimentação das cargas da área de recebimento para a área de expedição. A prática de cross-docking pode ser visualizada na Figura 2.

0 cross-docking visa evitar armazenagens desnecessárias em centros de distribuição ou em locais que trabalham como tal. A essência dessa prática é o foco na utilização da consolidação de cargas, evitando a armazenagem.

\subsection{Administração de estoques}

0 fato de manter estoques está relacionado com a necessidade de disponibilizar o produto ou material no momento certo, porém há consenso entre as

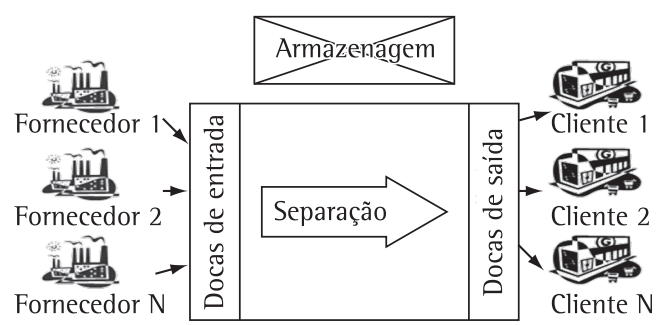

Figura 2. Cross-docking. Fonte: Adaptado de Pires (2004). empresas no sentido de eliminar ou reduzi-los ao mínimo possível, tentando adequar-se a um dos pressupostos da GCS.

0 equilíbrio entre custos e objetivos constitui-se verdadeiro desafio para as empresas. É importante ressaltar que nem sempre é possível o atendimento a 100\% dos clientes: o enfoque do gerenciamento logístico integrado sugere que as necessidades de serviço dos clientes devem ser satisfeitas dentro dos limites razoáveis de custo. Quanto maior for o nível de serviço da empresa, maiores serão seus custos, pois se a meta da empresa é entregar sempre no menor tempo e com a maior disponibilidade de produtos possível, deve estar ciente de que terá seus custos com transportes e estoques maximizados.

Alguns conceitos e técnicas têm sido adotados no intuito de minimizar os custos com estoques, enquanto garantem a disponibilidade dos produtos, dentre eles o JIT, a curva $\mathrm{ABC}$, o milk run (MR) e diversos sistemas e tecnologias de informações, que serão tratados nas seções seguintes.

\subsubsection{Just-in-time (JIT)}

Para Christopher (1997), de todos os conceitos e técnicas que surgiram, nas últimas décadas, a filosofia JIT é uma das que vieram para ficar. De acordo com esse conceito, nenhum produto deve ser fabricado, nenhum componente deve ser pedido enquanto não houver necessidade. Essencialmente, o JIT adota o conceito de puxar a produção, na qual a demanda puxa os produtos em direção ao mercado. 0 fluxo de componentes pertinentes a esses produtos também é determinado pela mesma demanda. 0 JIT contrasta com o sistema atual de empurrar, no qual os produtos são fabricados ou montados em lotes, antecipando a demanda, e são posicionados na CS como reguladores entre as várias funções e entidades.

\subsubsection{Curva $A B C$}

Outra técnica utilizada pelas empresas visando redução de custos com manutenção de estoques é a curva $A B C$, uma das mais antigas e conhecidas, sendo ainda utilizada por muitas empresas. Segundo Ching (2001), baseia-se no raciocínio do diagrama de Pareto, em que nem todos os itens têm a mesma importância, e a atenção deve ser dada para os mais significativos. Adotando esse raciocínio na administração de estoques, entende-se que nem todos os itens estocados merecem a mesma atenção ou precisam manter a mesma disponibilidade para satisfazer os clientes. 


\subsubsection{Modelo milk run (MR) de suprimento}

0 modelo MR ou rota do leite surgiu como alternativa para a concentração ou consolidação de um volume adequado de materiais, possibilitando a redução de custos com estoques e transporte que impacta diretamente no custo do produto final. 0 MR permite às indústrias manter seu nível de estoque muito baixo, ou seja, quase zero. Constitui-se numa estratégia que envolve um transportador que coleta a produção de vários fornecedores e os entrega de uma só vez.

Para Pires (2004), o principal objetivo do MR é reduzir custos logísticos de abastecimento por meio de economias de escala e racionalização das rotas, bem como aumentar a confiabilidade do processo. A lógica desse modelo é ter um sistema de suprimento com roteiros e horários predefinidos para as coletas de materiais junto aos fornecedores, cujo processo é ilustrado na Figura 3.

No sistema MR, a montadora está encarregada de coletar as peças diretamente nas empresas fornecedoras ou contratar terceiros, cujos custos de transporte ficam a cargo da própria montadora, ou seja, as compras são feitas no sistema FOB (MOURA, 2000).

\subsection{Sistemas e tecnologias de informação (TI) integrando a cadeia de suprimentos}

Para dar suporte a todas as mudanças ocorridas no ambiente empresarial e possibilitar que as atividades do sistema logístico sejam administradas corretamente, tornou-se necessária a utilização de sistemas de informação logísticos ou de GCS, viabilizados tecnicamente por meio da Tl. Essa afirmação é corroborada pelos autores Bowersox e Closs (2001). Entre esses sistemas e tecnologias estão o ERP, software de GCS, ECR, EDI e VMI, que são também abordados na pesquisa junto aos respondentes.

\section{Classificação da pesquisa}

Quanto à classificação da pesquisa, do ponto de vista de sua natureza é aplicada, segundo Silva e Menezes (2001), por envolver verdades e interesses locais. De acordo com seus objetivos, é considerada exploratória e descritiva, pois visa descrever com exatidão os fenômenos da realidade estudada e travar maior conhecimento do problema, por meio de pesquisas bibliográficas, levantamento de dados e estudo de caso conforme define Gil (1999).

No que se refere à forma de abordagem do problema, classifica-se como qualitativa, tendo como foco as características e a natureza do problema estudado. Por se tratar de pesquisa descritiva, não requer o uso de técnicas e métodos estatísticos, pois o processo e seu significado são os focos principais da abordagem.

0 tipo de amostragem escolhido para o presente trabalho foi por acessibilidade ou por conveniência, que de acordo com Gil (1999) não requer alto rigor estatístico. Para selecionar a amostra de montadoras e fornecedores do segmento automotivo, consultou-se o site da ANFAVEA - Associação Nacional de Fabricantes de Veículos Automotores.

Do ponto de vista dos procedimentos técnicos a pesquisa foi realizada em duas partes: a primeira se constituiu em uma revisão bibliográfica em

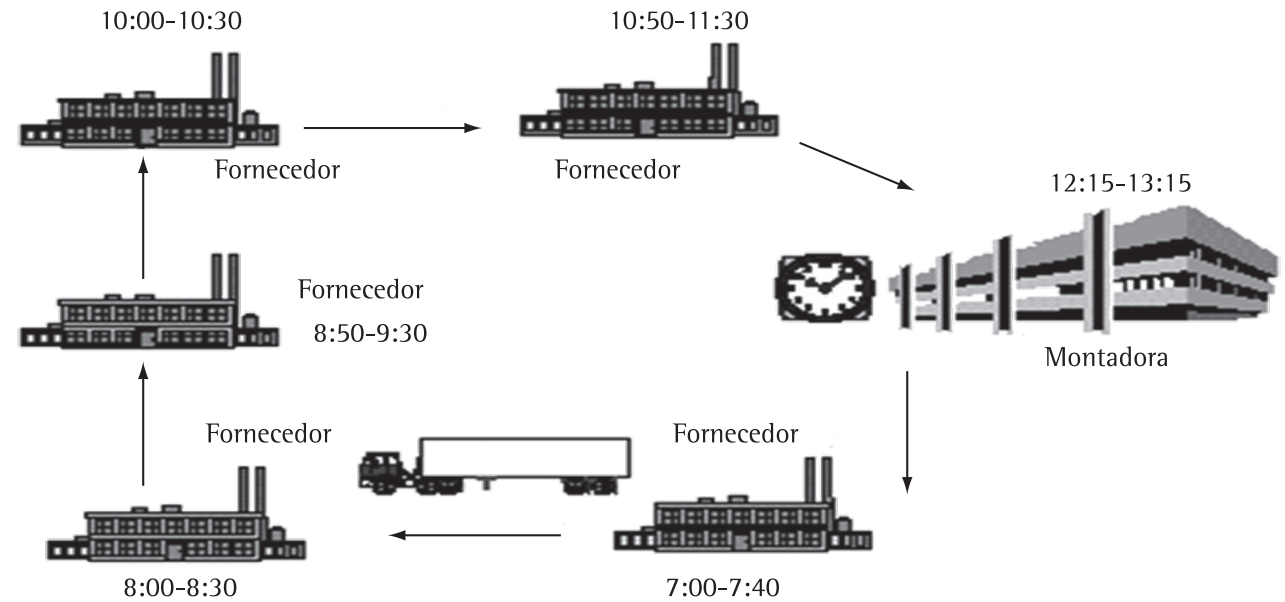

Figura 3. Sistema de coleta integrada de peças milk run. Fonte: Apostila da Ryder Integrated Logistics - GM Brasil (1999), apud Moura (2000). 
fontes primárias e secundárias e a segunda parte em um levantamento, por meio da aplicação de questionários, que se constitui principal forma de coleta de dados. 0 questionário abrangeu aspectos relativos ao conhecimento e formalização da logística e GCS; desenvolvimento de fornecedores e parcerias; administração de estoques; compras; transporte no processo de suprimentos; operadores logísticos; sistemas de informação e tecnologias na GCS.

\section{Coleta e tratamento dos dados}

A coleta de dados da presente pesquisa foi realizada por meio do envio de questionários à amostra selecionada na listagem disponível no endereço eletrônico da ANFAVEA, composta de 23 montadoras e 50 fornecedores da indústria automotiva. Os questionários foram mandados pelo correio convencional e eletrônico, cujo prazo de retorno foi informado aos respondentes. Obteve-se um retorno de 9 questionários das montadoras, o que representa 39\%, e 32 questionários dos fornecedores, que constituem 64\%.

Os dados foram tratados aplicando a estatística simples, ou seja, não foi utilizado nenhum método ou modelo de alto rigor estatístico. Cabe ressaltar que como a pesquisa não possui tal rigor estatístico, não se intenciona afirmar que a situação encontrada ilustra a realidade da população de indústrias do ramo pesquisado, mas procura demonstrar uma tendência de comportamento delas.

\section{Análise dos dados e resultados}

0 objetivo da pesquisa foi verificar o nível de formalização da LS na indústria automotiva, envolvendo conceitos e ferramentas tecnológicas que visam otimizar suas atividades. Tendo em vista que, sob a perspectiva do conceito de GCS, os membros da cadeia devem trabalhar em conjunto, e que quaisquer problemas oriundos nas partes envolvidas prejudicam toda a cadeia, cujos aspectos foram verificados nas montadoras e seus fornecedores.

Tratando-se da identificação e localização das empresas pesquisadas, essas montadoras localizam-se, predominantemente, em três estados, a saber: 56\% em São Paulo, 33\% no Paraná e 11\% no Rio Grande do Sul. Essas regiões possuem maior infraestrutura e melhor entroncamento rodoviário, propiciando a existência de: $22 \%$ de montadoras de máquinas agrícolas, $56 \%$ de automóveis utilitários e $22 \%$ de caminhões. Quanto ao porte delas, constatou-se que 56\% são multinacionais e 44\% constituem-se em grandes empresas. Já no que tange aos fornecedores, das 32 empresas pesquisadas $81 \%$ se constituem de fornecedores e $19 \%$ de fornecedores sistemistas. No que se refere à localização deles, 44\% concentram-se na grande São Paulo, 38\% no Paraná, 6\% em Minas Gerais e Rio Grande do Sul e apenas 3\%, na Bahia e outros estados. Em relação ao porte das empresas pesquisadas, 63\% são de médio porte, 19\% de grande porte, $13 \%$ multinacionais e $6 \%$ pequenas empresas.

Na Tabela 1, são mostrados o panorama relativo aos estoques e a condição de manutenção destes pelas montadoras e fornecedores. No que se refere à atividade logística de administração de estoques, verificou-se que 89\% das montadoras mantêm estoques, contra apenas $11 \%$ que não mantêm. Quanto ao volume deles, verificou-se que 78\% conservam baixos níveis de estoques, ou seja, somente estoque de segurança, enquanto 11\% mantêm níveis altos, produzindo para empurrar, e $11 \%$ produzem somente para a demanda puxada. Cerca de 78\% das montadoras pesquisadas acredita que o nível de serviço logístico está diretamente associado à atividade de administração de estoques e $22 \%$ afirmaram que o nível de serviço logístico não está, necessariamente, relacionado ao fato de manter estoques.

Constatou-se que a grande maioria dos fornecedores, ou seja, 94\% mantêm estoques contra apenas $6 \%$ que não mantêm. Já em relação aos níveis de estoque, 63\% das empresas disseram que seu nível é baixo e que mantêm somente estoque de segurança, 22\% afirmaram não ter estoques, ou seja, produzem somente pela demanda puxada, e

Tabela 1. Resultados referentes à administração de estoques.

\begin{tabular}{|c|c|c|c|}
\hline Q & ltens de pesquisa & $\begin{array}{l}\text { Montadoras } \\
(\%)\end{array}$ & $\begin{array}{l}\text { Fornecedores } \\
\qquad(\%)\end{array}$ \\
\hline \multirow[t]{3}{*}{1} & Manutenção de estoques: & & \\
\hline & Sim & 89 & 94 \\
\hline & Não & 11 & 6 \\
\hline \multirow[t]{4}{*}{2} & Níveis de estoques: & & \\
\hline & $\begin{array}{l}\text { Alto, a empresa produz } \\
\text { para estocar-produção } \\
\text { empurrada }\end{array}$ & 11 & 16 \\
\hline & $\begin{array}{l}\text { Baixo, a empresa mantém } \\
\text { somente estoque de } \\
\text { segurança }\end{array}$ & 78 & 63 \\
\hline & $\begin{array}{l}\text { A empresa produz somente } \\
\text { para a demanda-produção } \\
\text { puxada }\end{array}$ & 11 & 22 \\
\hline \multirow[t]{3}{*}{3} & $\begin{array}{l}\text { Nível de serviço associado a } \\
\text { estoques: }\end{array}$ & & \\
\hline & Sim & 78 & 94 \\
\hline & Não & 22 & 6 \\
\hline
\end{tabular}

Fonte: Os autores. 
16\% relataram que seu nível de estoques é alto, produzindo pela demanda empurrada. Ainda foi possivel constatar que $94 \%$ das empresas pesquisadas acreditam que o nível de estoques está diretamente relacionado ao nível de serviço oferecido aos clientes (montadora).

Comparativamente, percebe-se que fornecedores e montadoras mantêm estoques e que o nível é baixo, além de concordarem que o nível de serviço logístico está diretamente relacionado à manutenção de estoques. Devido às incertezas no abastecimento, ambos, montadoras e fornecedores, julgam necessária a manutenção de estoques para suprir uma possível falta. Na Tabela 2 é apresentado o resultado da adoção da filosofia JIT para a otimização no processo de abastecimento. 0 percentual de montadoras que adota parcialmente alguma ferramenta JIT em seus processos é de $78 \%$, contra $11 \%$ que adotam totalmente e $11 \%$ que pretendem adotar. Dentre as ferramentas JIT utilizadas, constatou-se que 32\% adotam o kanban para puxar os processos produtivos, 24\% o kaizen, visando melhoria contínua, $24 \%$ a ferramenta $5 S$ com o objetivo de racionalizar o ambiente de trabalho e $20 \%$ adotam a ferramenta keiretsu, que pressupõe parcerias entre fornecedores e clientes. Percebe-se, com a análise desses dados, que grande parte das montadoras pesquisadas acredita que o JIT é uma das soluções para racionalização de recursos nos processos produtivos, bem como a utilização de suas ferramentas proporciona maior confiabilidade entre negociações de cliente e fornecedores.

No que tange aos fornecedores, constatou-se que $78 \%$, a grande maioria, adotam o JIT parcialmente, enquanto apenas 9\% o fazem totalmente. Quanto às ferramentas usadas pelas empresas pesquisadas, observa-se que 33\% adotam o kanban para puxar sua produção, e também 33\% utilizam os 5 S visando melhoria do ambiente de trabalho e, ainda, $27 \%$ adotam o kaizen objetivando a melhoria contínua. Quando se confrontam os dados, percebe-se que existe convergência nas práticas JIT adotadas por montadoras e fornecedores, o que é favorável na implantação da GCS, visto que essa filosofia pressupõe uma ligação mais próxima entre as partes, visando estabelecer relacionamentos confiáveis e duradouros.

Foi possível verificar os benefícios esperados com a utilização da filosofia JIT nos fornecedores, dessa forma constatou-se que os mais cotados, de acordo com as montadoras, são: menores níveis de estoques e espaço de estocagem com $31 \%$ de escolha por parte das montadoras; tempo de reposição reduzido apresentou $21 \%$ das
Tabela 2. Resultados referentes à adoção da filosofia JIT.

\begin{tabular}{|c|c|c|c|}
\hline Q & Itens de pesquisa & $\begin{array}{l}\text { Montadoras } \\
\quad(\%)\end{array}$ & $\begin{array}{c}\text { Fornecedores } \\
(\%)\end{array}$ \\
\hline \multirow[t]{5}{*}{4} & Adoção do just-in-time - JIT: & & \\
\hline & Sim, parcialmente & 78 & 78 \\
\hline & Sim, totalmente & 11 & 9 \\
\hline & Não & - & 6 \\
\hline & Pretende adotar & 11 & 6 \\
\hline \multirow[t]{5}{*}{5} & Ferramentas JIT adotadas: & & \\
\hline & kanban & 32 & 33 \\
\hline & kaizen & 24 & 27 \\
\hline & $5 S$ & 24 & 33 \\
\hline & keiretsu & 20 & 8 \\
\hline \multirow[t]{7}{*}{6} & $\begin{array}{l}\text { Benefícios esperados com a } \\
\text { implantação do JIT: }\end{array}$ & & \\
\hline & $\begin{array}{l}\text { Redução do custo de } \\
\text { compras }\end{array}$ & 17 & 16 \\
\hline & $\begin{array}{l}\text { Diminuição do número } \\
\text { de fornecedores e da } \\
\text { burocracia }\end{array}$ & 7 & 8 \\
\hline & $\begin{array}{l}\text { Menores níveis e espaços } \\
\text { de estocagem }\end{array}$ & 31 & 32 \\
\hline & $\begin{array}{l}\text { Tempo de reposição } \\
\text { reduzido }\end{array}$ & 21 & 15 \\
\hline & $\begin{array}{l}\text { Melhores níveis de serviço } \\
\text { aos clientes }\end{array}$ & 14 & 22 \\
\hline & $\begin{array}{l}\text { Redução da perda de } \\
\text { matérias-primas e refugo }\end{array}$ & 10 & 7 \\
\hline \multirow[t]{8}{*}{7} & $\begin{array}{l}\text { Mudanças esperadas } \\
\text { no relacionamento com } \\
\text { fornecedores por meio do JIT: }\end{array}$ & & \\
\hline & Contratos de longo prazo & 3 & 7 \\
\hline & $\begin{array}{l}\text { Demandas previsíveis com } \\
\text { solicitações flexíveis }\end{array}$ & 22 & 18 \\
\hline & $\begin{array}{l}\text { Comunicação das } \\
\text { mudanças mais rápida, } \\
\text { em tempo real }\end{array}$ & 30 & 20 \\
\hline & $\begin{array}{l}\text { Produtos de alta qualidade } \\
\text { e com constância }\end{array}$ & - & 18 \\
\hline & $\begin{array}{l}\text { Tempos de entrega curtos } \\
\text { e garantidos }\end{array}$ & 30 & 28 \\
\hline & $\begin{array}{l}\text { Proximidade dos } \\
\text { fornecedores, inclusive } \\
\text { física }\end{array}$ & 15 & 6 \\
\hline & Nenhum & - & 2 \\
\hline
\end{tabular}

Fonte: Os autores.

respostas, e redução do custo de compras, 17\%. No que se refere ao que as montadoras buscam atingir com a adoção do JIT em seus processos, verificou-se que 30\% das empresas pesquisadas acreditam obter comunicação das mudanças mais rápido; também 30\% creem que os tempos de entrega se tornarão mais curtos e garantidos, e $22 \%$ esperam obter demandas previsíveis, com solicitações flexíveis.

Já em relação aos fornecedores, 28\% das empresas apontaram o fator de tempos de entregas mais curtos e garantidos; a comunicação das mudanças com maior rapidez foi escolhida por 
$20 \%$ dos fornecedores, e os benefícios relativos às demandas previsíveis, com solicitações flexíveis e produtos de alta qualidade e com constância, foram apontados por $18 \%$ dos respondentes. No que se refere às mudanças no relacionamento com fornecedores, constatou-se que 32\% das empresas apontaram os fatores menores níveis de estoques e espaços de estocagem, 22\% afirmaram ser a redução da perda de matérias-primas e refugos uma das principais mudanças, e 16\% falaram da redução dos custos de compras, além de 15\% terem apontado o tempo de reposição reduzido.

Efetuando-se um comparativo dos dados dos fornecedores com os das montadoras, nota-se que os benefícios esperados e as mudanças percebidas com a implantação do JIT coincidiram, o que indica que a linha de pensamento de ambos converge, pois de acordo com a literatura a adoção do JIT é uma das ações necessárias à aceitação das mudanças advindas da implantação do conceito de GCS. Na Tabela 3 são apresentados os resultados sobre a adoção da curva $\mathrm{ABC}$ e do modelo milk run no processo de abastecimento. Todas as montadoras pesquisadas alegaram adotar a curva $A B C$, e percebe-se que um percentual reduzido de fornecedores não a adota ou pretende adotá-la, enquanto a grande maioria, ou seja, $88 \%$ das empresas pesquisadas a adotam como forma de priorizar os investimentos em estoques em itens de maior relevância, enquanto minimiza o valor investido nos itens de menor relevância, tornando possivel, dessa forma, a redução de custos. Essa prática converge com a opinião das montadoras, que demonstra que a totalidade delas acredita ser esta prática importante para a minimização de custos com estoques.

Tabela 3. Resultados referentes à adoção da curva $A B C$ e do modelo MR.

\begin{tabular}{|c|c|c|c|}
\hline Q & Itens de pesquisa & $\begin{array}{c}\text { Montadoras } \\
(\%)\end{array}$ & $\begin{array}{c}\text { Fornecedores } \\
\qquad(\%)\end{array}$ \\
\hline \multirow[t]{4}{*}{8} & $\begin{array}{l}\text { Curva } \mathrm{ABC} \text { na administração } \\
\text { de estoques: }\end{array}$ & & \\
\hline & Sim & 100 & 88 \\
\hline & Não & - & 6 \\
\hline & Pretende adotar & - & 6 \\
\hline \multirow[t]{6}{*}{9} & $\begin{array}{l}\text { Adoção do modelo de } \\
\text { abastecimento milk run: }\end{array}$ & & \\
\hline & $\begin{array}{l}\text { Sim, totalmente (com } \\
\text { todos os fornecedores) }\end{array}$ & 11 & 6 \\
\hline & $\begin{array}{l}\text { Sim, parcialmente (com } \\
\text { alguns fornecedores) }\end{array}$ & 78 & 38 \\
\hline & Pretende adotar & - & 3 \\
\hline & Os clientes adotam & - & 50 \\
\hline & Não adotam & 11 & 3 \\
\hline
\end{tabular}

Fonte: Os autores.
0 modelo MR de abastecimento estabelece roteiros e horários predefinidos para a coleta de mercadorias nos fornecedores, visando reduzir custos com transporte, tempos de entrega e maior confiabilidade. De acordo com a revisão da literatura, essa é uma prática bastante utilizada na CS da indústria automotiva, o que se confirma com a análise dos dados das montadoras, demonstrando que a grande maioria, ou seja, $78 \%$ a adotam parcialmente com alguns fornecedores, enquanto $11 \%$ a utilizam com todos seus fornecedores e $11 \%$ não a usam. Já em relação aos fornecedores, $50 \%$ afirmaram que seus clientes (montadoras) adotam o modelo MR, enquanto 38\% responderam que o adotam parcialmente com alguns de seus fornecedores. Esses resultados denotam a preocupação, principalmente, das montadoras em tornar ágil o abastecimento e incrementar a confiabilidade no processo de coleta de materiais para a produção junto aos fornecedores.

A Figura 4 é apresentado com o intuito de verificar o processo de suprimentos/compras, visto que tem influência direta no relacionamento entre montadoras e seus fornecedores, maximizando recursos e minimizando custos da empresa.

Constatou-se que as principais ações de apoio que essa atividade logística oferece, adotadas pelas montadoras, são: $23 \%$ acreditam ser o relacionamento com fornecedores, também 23\% acham ser a qualificação dos fornecedores, 19\% o desenvolvimento de produtos pelo fornecedor, ainda $19 \%$ acreditam ser o desenvolvimento de novos materiais pelos fornecedores, e 16\% afirmaram que essa atividade auxilia na redução da base de fornecedores.

Quanto aos fornecedores, 32\% apontaram que adotam na sua atividade $\mathrm{LS} /$ compras a ação de qualificação dos fornecedores, 26\% o desenvolvimento de relacionamentos, $17 \%$ a redução do número de fornecedores e 14\% o desenvolvimento de novos materiais, o que indica que as empresas pesquisadas estão operando de acordo com o conceito de GCS.

Comparando-se esses dados, observa-se que houve congruência nas opções escolhidas com as apontadas pelos fornecedores, possibilitando que as negociações entre montadora e fornecedores e entre estes e subfornecedores sejam mais homogêneas, concordando com o apresentado no referencial teórico, em que os autores citados afirmam que, adotando-se essas práticas na função de suprimentos/compras dos membros da CS, a implantação do conceito de GCS torna-se mais factível. 


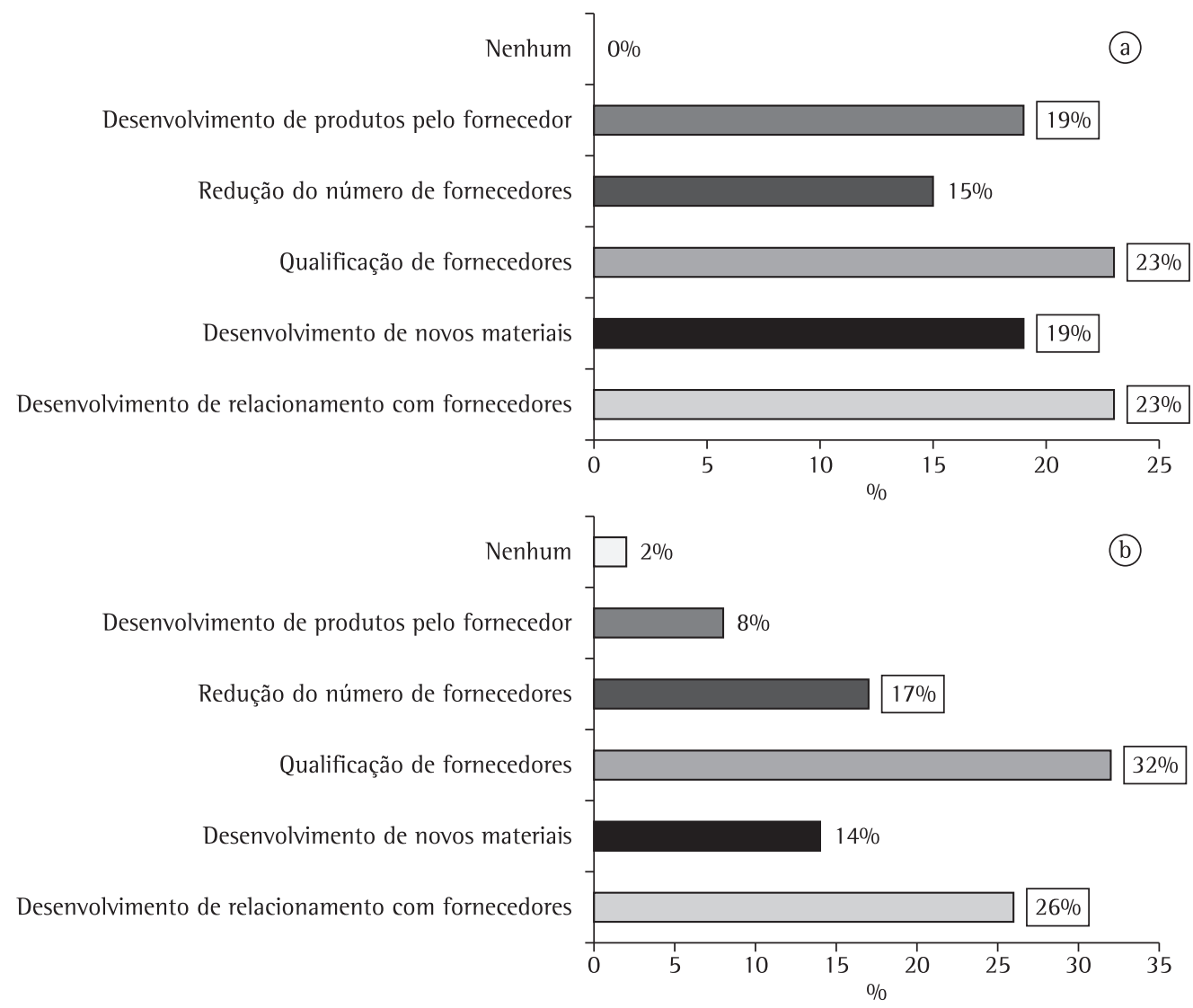

Figura 4. Resultados de Suprimentos/Compras. Fonte: Os autores.

A Tabela 4 apresenta o impacto das atividades de transportes e operadores logísticos no processo de abastecimento das montadoras.

Analisando-se a atividade de transporte da empresa, que atua diretamente na disponibilidade de materiais para a produção e na variação de custos do produto acabado, verifica-se que 67\% das montadoras pesquisadas operam com frete pago pelo fornecedor ou pelo cliente, o que depende da negociação, enquanto 33\% adotam o sistema FOB, confirmando a tendência demonstrada na revisão da literatura. Quanto à frota de veículos e serviços de transporte utilizados, constatou-se que a totalidade das montadoras subcontrata sua atividade de transporte e 55\% adotam a prática cross-docking visando o transbordo sem estocagem e a consolidação de vários fornecedores em uma só carga, contra 45\% que não adotam a prática.

Tratando-se dos fornecedores, percebe-se que a maioria não tem uma opção definida, dependendo da negociação com seus clientes, 25\% alegaram adotar o FOB e 16\% afirmaram usar o CIF. Quanto ao cross-docking, 25\% dos fornecedores o adotam, $59 \%$ não e $16 \%$ pretendem adotá-lo.
A tendência apontada pela literatura é a de que as empresas adotem o FOB, o que não foi confirmado na pesquisa, pois as empresas respondentes, tanto se tratando de fornecedores como das montadoras, alegam escolher o meio de compras, de acordo com a negociação no momento, pois dessa forma podem analisar que tipo de coleta de materiais é mais confiável e com que urgência necessitam desses materiais. A literatura também mostra que a adoção do sistema cross-docking é vantajosa no sentido de reduzir custos com armazenagem e transportes, e percebe-se pelos percentuais encontrados que essa prática está mais consolidada nas montadoras, no entanto nota-se o interesse dos fornecedores em adotá-la.

0 questionário de pesquisa procurou também verificar se as empresas terceirizam algumas de suas atividades logísticas, delegando-as a operadores logísticos, o que demonstrou que 100\% das montadoras pesquisadas acreditam que essa prática viabiliza a redução de custos, principalmente com pessoal, e permite à empresa manter seu foco nos negócios. Quanto às atividades desempenhadas por 
Tabela 4. Resultados de transportes no processo de suprimentos e operadores logísticos.

\begin{tabular}{|c|c|c|c|}
\hline Q & Itens de pesquisa & $\begin{array}{c}\text { Montadoras } \\
(\%)\end{array}$ & $\begin{array}{c}\text { Fornecedores } \\
(\%)\end{array}$ \\
\hline \multirow[t]{4}{*}{10} & $\begin{array}{l}\text { Meio de operação de } \\
\text { compras (frete): }\end{array}$ & & \\
\hline & $\mathrm{CIF}$ & - & 16 \\
\hline & FOB & 33 & 25 \\
\hline & Depende da negociação & 67 & 59 \\
\hline \multirow[t]{3}{*}{11} & Atividade de transporte: & & \\
\hline & Própria & - & 16 \\
\hline & Terceirizada & 100 & 84 \\
\hline \multirow[t]{4}{*}{12} & $\begin{array}{l}\text { Adoção do sistema } \\
\text { cross-docking: }\end{array}$ & & \\
\hline & $\begin{array}{l}\text { Sim; atividades delegadas } \\
\text { aos operadores logísticos }\end{array}$ & 55 & 25 \\
\hline & Não & 45 & 59 \\
\hline & Pretende operar & - & 16 \\
\hline \multirow[t]{4}{*}{13} & $\begin{array}{l}\text { Adoção de operadores } \\
\text { logisticos: }\end{array}$ & & \\
\hline & Sim & 100 & 25 \\
\hline & Não & - & 69 \\
\hline & Pretende trabalhar & - & 6 \\
\hline \multirow[t]{8}{*}{14} & Armazenagem & & \\
\hline & $\begin{array}{l}\text { Transportes } \\
\text { (cross-docking, milk run, } \\
\text { convencional) }\end{array}$ & 19 & 22 \\
\hline & $\begin{array}{l}\text { Recolhimento de } \\
\text { embalagens e resíduos }\end{array}$ & 34 & 36 \\
\hline & $\begin{array}{l}\text { Suprimentos } \\
\text { (compras/obtenção) }\end{array}$ & 19 & 14 \\
\hline & $\begin{array}{l}\text { Manutenção } \\
\text { (equipamentos/ } \\
\text { instalações) }\end{array}$ & 3 & - \\
\hline & Embalagem e manuseio & 3 & 7 \\
\hline & $\begin{array}{l}\text { Manutenção de sistemas } \\
\text { de informação }\end{array}$ & 15 & 5 \\
\hline & Nenhuma & 7 & 7 \\
\hline
\end{tabular}

Fonte: Os autores.

essas empresas, vistas muitas vezes como parceiras, observa-se que 34\% terceirizam a atividade de transporte, que é a que exige maior investimento em infraestrutura emanutenção, 18\% delegamaatividade de armazenagem e recolhimento de embalagens e resíduos. Dessa forma, confirma-se a tendência das montadoras em coordenar a CS, enquanto deixam para os parceiros o desenvolvimento de atividades logísticas, que embora muito importantes para o nível de serviço logístico contribuem com grande parcela de custos e tempo.

A maioria dos fornecedores, ou seja, 69\% não trabalham com operadores logísticos, enquanto apenas 25\% afirmaram trabalhar. No que se refere às atividades desempenhadas pelos operadores logísticos, constatou-se que a atividade de transporte apresentou um percentual de escolha de $36 \%$, a de armazenagem $22 \%$, e a atividade de recolhimentos de embalagens e resíduos um percentual de 14\%.
Considerando-se que as primeiras duas atividades apontadas são as que mais geram custos para as empresas, é salutar que os fornecedores procurem minimizar recursos nelas investidos, podendo concentrar seu foco em suas atividades principais. Já no que se refere às montadoras, verifica-se que essa prática está mais consolidada, uma vez que a totalidade delas afirmou operar com trabalhadores logísticos, o que provavelmente contribui na redução de seus custos.

A Tabela 5 apresenta o panorama dos resultados referentes a sistemas de informações e tecnologias de informação integradoras do processo de abastecimento. Quanto ao ERP, questionando-se sua implantação pelas montadoras, visando a integração de suas atividades internas e eliminando controles paralelos e burocracia, $67 \%$ afirmaram que o tinham implantado, 22\% alegaram que pretendem implantá-lo e $11 \%$ não o possuem. Ainda, $67 \%$ das empresas utilizam do ERP, o módulo de operações e SCM/GCS, 55\% o de gestão financeira/contábil/fiscal (GFCF) e 44\%, o de gestão de recursos humanos. Enquanto 67\% acreditam que a implantação do ERP possibilitou melhoria na integração de atividades e racionalização dos processos da empresa, contra $33 \%$ que não acreditam nessa afirmação, o que torna perceptível a importância de um sistema de informação gerencial, em nível operacional, que organize os processos da empresa, possibilitando que no momento da integração com os fornecedores ela não tenha gargalos e compartilhe informações confiáveis com os parceiros.

Visando verificar se os fornecedores pesquisados possuem integração de seus processos internos através de sistemas de informação, constatou-se que $72 \%$ possuem o sistema ERP implantado, enquanto 16\% pretendem implantá-lo e apenas 13\% não o possuem. Quanto aos módulos implantados, verificou-se que $40 \%$ usam o módulo de (GFCF) e 33\% o módulo de operações e SCM. De acordo com a literatura, a utilização do ERP aumenta a confiabilidade nas informações trocadas entre membros da CS, o que embasa as decisões em nível operacional e racionaliza os recursos das empresas. Já no que se refere aos fornecedores terem percebido melhorias com a implantação do sistema ERP, a grande maioria, ou seja, 81\% acreditam que sim, o que confirma o apresentado pela literatura a respeito. Fato que converge com a opinião das montadoras, onde também a maioria percebe a necessidade do ERP, no sentido de racionalizar seus processos, principalmente no que tange a operações e SCM, pois se os fornecedores não operarem com um sistema de informações confiável que organize seus processos internos, a 
Tabela 5. Resultados do módulo VIl - Sl e Tl na GCS.

\begin{tabular}{|c|c|c|c|}
\hline Q & Itens de pesquisa & $\begin{array}{l}\text { Montadoras } \\
(\%)\end{array}$ & $\begin{array}{c}\text { Fornecedores } \\
(\%)\end{array}$ \\
\hline \multirow[t]{4}{*}{15} & ERP implantado: & & \\
\hline & Sim & 67 & 72 \\
\hline & Não & 13 & 13 \\
\hline & Pretende implantar & 16 & 16 \\
\hline \multirow[t]{5}{*}{16} & $\begin{array}{l}\text { Módulos de ERP } \\
\text { implantados: }\end{array}$ & & \\
\hline & $\begin{array}{l}\text { Operações e Supply Chain } \\
\text { Management }\end{array}$ & 67 & 33 \\
\hline & $\begin{array}{l}\text { Gestão financeira/ } \\
\text { contábil/fiscal }\end{array}$ & 55 & 40 \\
\hline & $\begin{array}{l}\text { Gestão de recursos } \\
\text { humanos }\end{array}$ & - & 21 \\
\hline & Nenhum & 11 & 7 \\
\hline \multirow[t]{4}{*}{17} & $\begin{array}{l}\text { Percepção de melhorias } \\
\text { advindas com o ERP: }\end{array}$ & & \\
\hline & Sim & 67 & 81 \\
\hline & Não & 33 & 6 \\
\hline & Sem alterações & - & 13 \\
\hline
\end{tabular}

integração com as montadoras se torna impossível. Na Tabela 6 são apresentados os resultados da evidência de usos de softwares relacionados a SCM e uso de demais meios de tecnologias integradoras de informação. Ainda, no que tange aos sistemas de $\mathrm{Tl}$, constatou-se que $78 \%$ das montadoras possuem algum módulo dos softwares de SCM que atuam estrategicamente implantados, e apenas 22\% estão em processo de implantação. No que se refere aos módulos implantados nas respectivas empresas, 18\% adotam o módulo de programação da produção, ao passo que os módulos de planejamento mestre, planejamento da demanda, WMS e compras por meio eletrônico apresentaram o mesmo percentual de 15\%, individualmente.

Ainda foi possível observar que a maioria das montadoras, ou seja, $89 \%$ acreditam que a implantação dos softwares de SCM/GCS possibilita aos gerentes tornar as operações mais eficientes, bem como entender melhor o impacto de suas decisões estratégicas, além de proporcionar a integração dos processos entre fornecedores e clientes, contra apenas $11 \%$ que acreditam não notar diferença após a implantação deles.

Constatou-se que 53\% dos fornecedores pesquisados possuem algum software implantado, $31 \%$ não têm nenhum e $16 \%$ estão em processo de implantação. Com relação aos módulos implantados, verificou-se que $18 \%$ usaram o de planejamento mestre, $18 \%$ o de programação da produção, 14\% não possuem nenhum módulo implantado, $11 \%$ o de planejamento de rede estratégico, 10\% possuem o de compras por meio eletrônico, 9\%
Tabela 6. Resultados da evidência de usos de softwares para $\mathrm{SCM}$ e tecnologias integradoras.

\begin{tabular}{|c|c|c|c|}
\hline Q & Itens de pesquisa & $\begin{array}{c}\text { Montadoras } \\
(\%)\end{array}$ & $\begin{array}{c}\text { Fornecedores } \\
(\%)\end{array}$ \\
\hline \multirow[t]{4}{*}{18} & $\begin{array}{l}\text { Software de SCM/GCS } \\
\text { implantado: }\end{array}$ & & \\
\hline & Sim & 78 & 53 \\
\hline & Não & - & 31 \\
\hline & $\begin{array}{l}\text { Está em processo de } \\
\text { implantação }\end{array}$ & 22 & 16 \\
\hline \multirow[t]{11}{*}{19} & $\begin{array}{l}\text { Módulos de software de } \\
\text { SCM implantados: }\end{array}$ & & \\
\hline & $\begin{array}{l}\text { Planejamento de rede } \\
\text { estratégico }\end{array}$ & 6 & 1 \\
\hline & Planejamento mestre & 15 & 18 \\
\hline & $\begin{array}{l}\text { Planejamento da } \\
\text { demanda }\end{array}$ & 15 & 11 \\
\hline & $\begin{array}{l}\text { Planejamento da } \\
\text { distribuição }\end{array}$ & 3 & - \\
\hline & $\begin{array}{l}\text { Planejamento de } \\
\text { inventário }\end{array}$ & 3 & 9 \\
\hline & $\begin{array}{l}\text { Programação da } \\
\text { produção }\end{array}$ & 18 & 18 \\
\hline & $\begin{array}{l}\text { TMS-Sistema de } \\
\text { gerenciamento de } \\
\text { transporte }\end{array}$ & 6 & - \\
\hline & $\begin{array}{l}\text { WMS-Sistema de } \\
\text { gerenciamento de } \\
\text { armazéns }\end{array}$ & 15 & 9 \\
\hline & $\begin{array}{l}\text { Compras por meio } \\
\text { eletrônico }\end{array}$ & 15 & 10 \\
\hline & Nenhum & 6 & 14 \\
\hline \multirow[t]{4}{*}{20} & $\begin{array}{l}\text { Eficiência com uso dos } \\
\text { softwares de SCM: }\end{array}$ & & \\
\hline & Sim & 89 & 88 \\
\hline & Não & - & 9 \\
\hline & Sem alterações & 11 & 3 \\
\hline \multirow[t]{5}{*}{21} & $\begin{array}{l}\text { Tecnologias integradoras } \\
\text { do processo de } \\
\text { abastecimento: }\end{array}$ & & \\
\hline & $\begin{array}{l}\text { ECR - Electronic } \\
\text { Consumert Response }\end{array}$ & - & - \\
\hline & $\begin{array}{l}\text { EDI - Electronic Data } \\
\text { Interchange }\end{array}$ & 73 & 75 \\
\hline & $\begin{array}{l}\mathrm{VM1} \text { - Vendor } \\
\text { Management Inventory }\end{array}$ & 9 & - \\
\hline & Nenhum & 18 & 25 \\
\hline
\end{tabular}

Fonte: Os autores.

o de planejamento de inventário; o de sistema de gerenciamento de armazém também apresentou percentual de $9 \%$.

Quanto à implantação desses softwares possibilitar aos gerentes a tomada de decisões com maior eficiência, bem como integrar os processos de fornecedores/montadoras, verificou-se que $88 \%$, ou seja, a maioria acredita que sim, contra apenas $3 \%$ que acham que não e $9 \%$ que não perceberam alterações com a implantação. 
Observa-se que os softwares de SCM/GCS, de acordo com a literatura, possibilitam maior integração entre os membros de uma CS, eliminando também estoques e custos com armazenagem, tendo em vista que possibilitam maior planejamento dos recursos além de otimizar o intercâmbio de informações, o que é corroborado pela pesquisa, considerando que a maioria das empresas percebe os benefícios gerados, além de os módulos mais utilizados serem relacionados diretamente a esses fatores.

As montadoras, em sua maioria, ou seja, 73\% utilizam o EDl, enquanto apenas 18\% não adotam nenhum sistema e/ou tecnologia e 9\% utilizam o VMI. Já em relação aos fornecedores, também a maioria, ou seja, 75\% adotam o EDI como principal $\mathrm{Tl}$ no intuito de integrar os processos de abastecimento de fornecedores e montadoras e 25\% não utilizam nenhum sistema.

Denota-se com esses dados que montadoras e fornecedores se preocupam com a agilidade e confiabilidade das informações decorrentes do abastecimento da produção, o que justifica o alto índice de adoção do EDI, porém as montadoras ainda não disponibilizam a utilização do VMI com seus fornecedores. 0 uso do VMl pressupõe a administração do estoque da montadora por seus fornecedores, e consequentemente transparência nas informações de demanda. A não utilização dessa tecnologia dificulta a redução de estoques em todos os elos da CS, tendo em vista que a demanda das montadoras é muito oscilante e os fornecedores se obrigam a manter estoques para garantir o atendimento.

\section{Considerações finais}

Diante das inúmeras mudanças no ambiente de negócios, as indústrias automotivas buscam constantemente soluções para gerenciar sua CS com sucesso, visando obter vantagens competitivas, o que se constitui em um dos seus maiores desafios. Muitas foram as iniciativas nesse sentido, desde o aperfeiçoamento de seus sistemas produtivos, a readequação de suas normas de qualidade e mais recentemente a necessidade de integração de sua CS. Nesse último ponto, surge a busca por parcerias entre clientes (montadoras) e seus fornecedores, baseadas na confiança e no crescimento mútuo. Uma das tendências mundiais é que fique a cargo das montadoras a coordenação dessa cadeia, enquanto os fornecedores trabalham no desenvolvimento do produto e na execução dos processos de montagem dos veículos.
Para responder ao objetivo geral da pesquisa, que consiste em verificar o nível de formalização da LS nas montadoras da indústria automotiva brasileira, foi necessário verificar os conceitos e ferramentas tecnológicas utilizados pelas montadoras e seus fornecedores no processo de abastecimento da produção. Tendo em vista que o gerenciamento logístico está incluído como um dos pressupostos da GCS, considera-se que é importante que as empresas parceiras operem de forma uniformizada.

Com a análise desses fatores, percebe-se que há congruência nas ações dos fornecedores e montadoras, bem como uma homogeneidade nos conceitos e ferramentas tecnológicas utilizados no processo de abastecimento da produção, visando a otimização de recursos materiais, financeiros e humanos, o que demonstra que existe compatibilidade no que se refere ao gerenciamento logístico em ambos os elos da CS; no entanto, percebe-se que nas montadoras essas práticas e capacidades estão mais desenvolvidas.

Tal homogeneidade é considerada altamente positiva, pois um dos pressupostos essenciais para que haja sucesso na implantação do conceito de GCS é a padronização das iniciativas adotadas e a troca de experiências, que beneficiam toda a CS da indústria automotiva.

\section{Referências}

ASSOCIAÇ̃̃O NACIONAL DOS FABRICANTES DE VEÍCULOS AUTOMOTORES - ANFAVEA. Anuário da Indústria Automotiva Brasileira. São Paulo, 2005.

ARBACHE, F. S. et al. Gestão de logística, distribuição e trade marketing. Rio de Janeiro: FGV, 2004.

BOWERSOX, D. J.; ClOSS, D. J. Logística Empresarial. São Paulo: Atlas, 2001.

CHING, H. Y. Gestão de estoques na cadeia de logística integrada. São Paulo: Atlas, 2001.

CHRISTOPHER, M. Logística e gerenciamento da cadeia de suprimentos. estratégias para a redução de custos e melhoria dos serviços. São Paulo: Pioneira, 1997.

DIAS, M. A. P. Administração de materiais: uma abordagem logística. São Paulo: Atlas, 1993.

GlL, A. C. Métodos e técnicas de pesquisa social. São Paulo: Atlas, 1999.

KILLEN, C. P. et al. Cooperative competitive strategies: an australian case study. Brazilian Journal of Operations \& Production Management, v. 1, n. 1, p. 11-27, 2004.

LACERDA, L. Armazenagem estratégica: analisando novos conceitos. Rio de Janeiro: UFRJ, 2000.

MARINI, L. M. O relacionamento e as novas configurações entre montadoras de automóveis e seus fornecedores. Dissertação (Mestrado em Engenharia de Produção) Universidade Federal de Santa Catarina, Florianópolis, 2003. 
MOURA, D. A. Caracterização e análise de um sistema de coleta programada de peças, "Milk Run”, na indústria automobilística nacional. Dissertação (Mestrado em Engenharia de Produção) - Universidade de São Paulo, São Paulo, 2000.

PIRES, S. R. Gestão da cadeia de suprimentos: conceitos, estratégias, práticas e casos. São Paulo: Atlas, 2004.

SCAVARDA, L. F. R.; HAMACHER, S. A evolução da cadeia de suprimentos da indústria automotiva no Brasil. In: ENCONTRO DA ASSOCIAÇÃO NACIONAL DOS PROGRAMASDEPÓS-GRADUAÇÃOEM ADMINISTRAÇÃO, 24., 2000, Florianópolis. Anais... Florianópolis: ENANPAD, 2000. (CD-ROM)
SILVA, E. L.; MENEZES, E. M. Metodologia da pesquisa e elaboração de dissertação. Florianópolis: UFSC, 2001.

WANKE, P. Logística, gerenciamento da cadeia de suprimentos e organização do fluxo de produtos. In: FIGUEIREDO, K. F.; FLEURY, P. F.; WANKE, P. Logística e gerenciamento da cadeia de suprimentos: planejamento do fluxo de produtos e dos recursos. São Paulo: Atlas, 2003.

\section{Agradecimento}

Os autores agradecem o suporte financeiro recebido da CAPES e às empresas do ramo automotivo que colaboraram para o êxito deste trabalho de pesquisa.

\section{Formalization of supply logistics: case of automakers and suppliers from Brazilian automotive industry}

\section{Abstract}

The automotive sector presents considerable initiatives in Supply Chain Management (SCM) which deserve to be recognized. The main objective of the research was to verify the level of formalization of supply logistics between Brazilian automakers and suppliers. In order to reach this objective, an applied, exploratory, descriptive and qualitative research project was implemented, using an inductive approach. The technical procedure used to collect data was a survey. The data collection was carried out through questionnaires and the research sample consisted of 23 automakers and 50 suppliers in the Brazilian automotive industry. 1t was perceived that the practices adopted by both are convergent, which constitutes an essential aspect for an effective implementation of SCM, however, it is necessary to emphasize that these practices are more developed in automakers.

Keywords

Automotive industry. Supply Chain Management. Supply logistics. 